\title{
Totally thoracoscopic repair of atrial septal defect without robotic assistance: A single-center experience
}

\author{
Zeng-Shan Ma, MD, PhD, ${ }^{\mathrm{a}}$ Ming-Feng Dong, MD, ${ }^{\mathrm{a}}$ Qiu-Yang Yin, MD, ${ }^{\mathrm{a}}$ Zhi-Yu Feng, MD, ${ }^{\mathrm{a}}$ and \\ Le-Xin Wang, MD, $\mathrm{PhD}^{\mathrm{b}}$
}

\begin{abstract}
Objective: The recent advent of robotically assisted surgery has enabled totally endoscopic repair of atrial septal defects and patent foramen ovale. This study investigates the feasibility and safety of totally endoscopic repair of an atrial septal defect through small incisions on the chest without robotic assistance.
\end{abstract}

\begin{abstract}
Methods: Forty patients ( 23 female patients; average age, $15.4 \pm 8.7$ years; age range, 6-47 years) with secundum-type ASDs were selected for this study. Cardiopulmonary bypass was achieved peripherally. Through 3-port incisions in the right chest, pericardiotomy, bicaval occlusion, atriotomy, and ASD repair were performed by a surgeon through a thoracoscopy.
\end{abstract}

\begin{abstract}
Results: The cardiopulmonary bypass and aortic crossclamp times were $56.2 \pm 21.1$ and $38.3 \pm 8.6$ minutes, respectively. The length of stay in the intensive care unit was $23.0 \pm 4.1$ hours. There were no mortalities and no major complications in this cohort. Patients were discharged from the hospital 4 to 6 days after the operation. Transesophageal echocardiographic analysis immediately after the operation and at 30 days showed complete closure of the defect without residual shunt.
\end{abstract}

Conclusions: Totally endoscopic atrial septal defect repair can be achieved without a robotically assisted surgical system. This technique is safe and effective and can be used as a therapeutic option for ASD. (J Thorac Cardiovasc Surg 2011;141:1380-3)

\begin{abstract}
Atrial septal defect (ASD) is one of the most common congenital cardiac defects. Many ASDs can now be closed with septal occluder devices through cardiac catheterization. ${ }^{1}$ However, the need for subsequent surgical rescue after catheter-based ASD repair was more common than reoperation in patients undergoing surgical closure. ${ }^{1}$ In addition, large ASDs might not be suitable for transcatheter closure and require primary surgical repair. ${ }^{2}$ Minimally invasive surgical approaches have been applied to repair ASDs to minimize surgical trauma and improve cosmetic results. ${ }^{3-6}$ In recent years, totally endoscopic techniques have also been developed for ASD closure. ${ }^{6-10}$ Totally endoscopic procedures require the aid of computer and robotic technologies and are associated with excellent success rates in ASD closure and low complication rates. ${ }^{4-8}$ Whether totally endoscopic ASD closure can be achieved
\end{abstract}

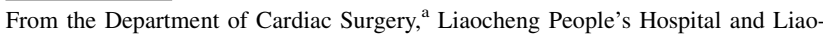
cheng Clinical School of Taishan Medical University, Liaocheng, Shandong, China; and the School of Biomedical Sciences, ${ }^{\text {b }}$ Charles Sturt University, Wagga Wagga, Australia.

Disclosures: Authors have nothing to disclose with regard to commercial support.

Received for publication June 4, 2010; revisions received July 28, 2010; accepted for publication Oct 17, 2010; available ahead of print Dec 20, 2010.

Address for reprints: Le-Xin Wang, MD, PhD, School of Biomedical Sciences, Charles Sturt University, Wagga Wagga, NSW 2678, Australia (E-mail: lwang@ csu.edu.au) or Zeng-Shan Ma, MD, PhD, Department of Cardiac Surgery, Liaocheng People's Hospital, Liaocheng, Shandong Province, 252000, P. R. China (E-mail: mazengshan31@163.com). 0022-5223/\$36.00

Crown Copyright $\subset 2011$ Published by Elsevier Inc. on behalf of The American Association for Thoracic Surgery

doi:10.1016/j.jtcvs.2010.10.028
}

without a robotically assisted surgical system has not been previously investigated. In this study we report our single-center experience with totally endoscopic repair of ASDs through 3 small incisions in the right chest.

\section{MATERIALS AND METHODS \\ Patient Selection}

This study was approved by the Institutional Review Board of Liaocheng People's Hospital. Written informed consent was obtained from all participants before the study. Between June 2009 and April 2010, patients with ASDs were selected from the Department of Cardiac Surgery for this study. The selection criteria were as follows: (1) 5 years of age or older with a body weight of $20 \mathrm{~kg}$ or more; (2) pulmonary arterial systolic pressure measured by means of echocardiographic analysis of $60 \mathrm{~mm}$ $\mathrm{Hg}$ or less; (3) no previous history of lung disease or operations on the right chest; and (4) no other cardiovascular diseases or chronic illnesses. Patients who were unable to meet all of the above selection criteria or unable to provide informed consent were excluded from this study.

\section{Anesthesia}

After induction of general anesthesia, a left-sided double-lumen endotracheal tube (for patients with body weight $\geq 50 \mathrm{~kg}$ ) or singlelumen endotracheal tube (body weight $<50 \mathrm{~kg}$ ) was placed to allow for single-lung ventilation. The respiration rate was set between 18 and 30 breaths/min, and the arterial oxygen saturation rate was maintained at greater than $97 \%$.

\section{Surgical Techniques}

The patient was positioned in the supine position with the right side of the body elevated to $15^{\circ}$ to $20^{\circ}$. After systemic heparinization, the right femoral artery and vein were accessed through an oblique incision along the inguinal crease, as previously reported by Bonaros and colleagues. ${ }^{10}$ A 24F/29F Carpentier double-lumen catheter (Medtronic, Inc, Minneapolis, Minn) was inserted through the right femoral vein into the inferior and 


\section{Abbreviations and Acronyms \\ $\mathrm{ASD}=$ atrial septal defect \\ $\mathrm{CPB}=$ cardiopulmonary bypass}

superior vena cava. The bypass circuit was completed by positioning a $17 \mathrm{~F}$ or $21 \mathrm{~F}$ catheter (Medtronic, Inc) in the abdominal aorta through the right femoral artery.

Three small incisions (ports) were made on the right side of the chest (Figure 1). Port $1(1-1.5 \mathrm{~cm})$ was located in the fourth intercostal space on the right side of the sternum (Figure 1). This port was for the insertion of surgical instruments, such as tissue forceps or suture needles, using the left hand (for a right-handed operator). Port $2(1-1.5 \mathrm{~cm})$ was for the entry of instruments, such as scissors, handled by the right hand of the operator and is located in the sixth intercostal space on a midclavicular line (Figure 1). Port $3(1.5-2.0 \mathrm{~cm})$ was located in the fifth intercostal space on the right midaxillary line (Figure 1). This port was for the placement of an endoscopic camera or thoracoscopy (Figure 2). A self-made plastic retractor was inserted into each of the 3 ports to keep them open and to facilitate the insertion or withdrawal of the instruments or thoracoscopy (Figure 2).

Once the 3 ports were secured, a pericardiotomy was performed, and 3 to 4 sutures were placed to suspend the pericardium. Caval snares were placed in the superior and inferior vena cavae to install total cardiopulmonary bypass (CPB). After $\mathrm{CPB}$ initiation and cooling to $32^{\circ} \mathrm{C}$, the thoracoscopy was placed through port 2 to visualize the root of the aorta. An aortic crossclamp was positioned on the ascending aorta (Figure 3). A needle was inserted through port 3 to the aortic root for the delivery of cold cardioplegic solution to achieve cardiac arrest (Figure 3). The thoracoscopy was repositioned through port 3 to visualize the right atrium. A tissue forceps and a scissors were entered through ports 1 and 2, respectively. After snaring of the superior and inferior vena cavae, the right atrium was opened from a site parallel to the atrioventricular annulus, and 4 stay sutures were placed on the incision to expose the intra-atrial structure. The ASD was closed with direct 4-0 Prolene sutures (Ethicon, Inc, Somerville, NJ; Figure 4). A bovine patch (Bairen Med Pharma Co, Beijing, China) was used to repair larger ASDS with running Prolene sutures.

After ASD closure, the aortic crossclamp was released. The patient was rewarmed and weaned from CPB. The integrity of the ASD closure was confirmed by means of transesophageal echocardiographic analysis. Protamine sulfate (1:1) was administered to counteract the actions of heparin. After adequate hemostasis was achieved, all instruments were removed from the chest, and a $24 \mathrm{~F}$ chest tube was inserted in the right pleural space through port 2 for drainage after removal of the cannulas and reconstruction of the right femoral artery and femoral vein.

\section{Perioperative Management}

Before surgical intervention, education and counseling were provided to all participants on surgical techniques, possible clinical outcomes, potential complications, and postoperative self-care measures. Lung function tests were routinely performed on all patients before the operation. The lungs were inflated every 20 minutes during the operation. After the operation, patients were monitored in the intensive care unit overnight and received low-frequency, high-volume mechanical ventilation with a peak end-expiratory pressure of 3 to $5 \mathrm{~cm} \mathrm{H}_{2} \mathrm{O}$. Bedside chest radiographic analysis was routinely performed in the intensive care unit to exclude complications in the lungs. Furosemide $(1 \mathrm{mg} / \mathrm{kg}$ administered intravenously once daily) and methylprednisolone $\left(0.5 \mathrm{mg} \cdot \mathrm{k}^{-1} \cdot \mathrm{d}^{-1}\right.$ administered intravenously once daily) were used in all patients to prevent pulmonary edema. Mechanical ventilation was ceased once the patient's hemodynamics and spontaneous respiration stabilized.

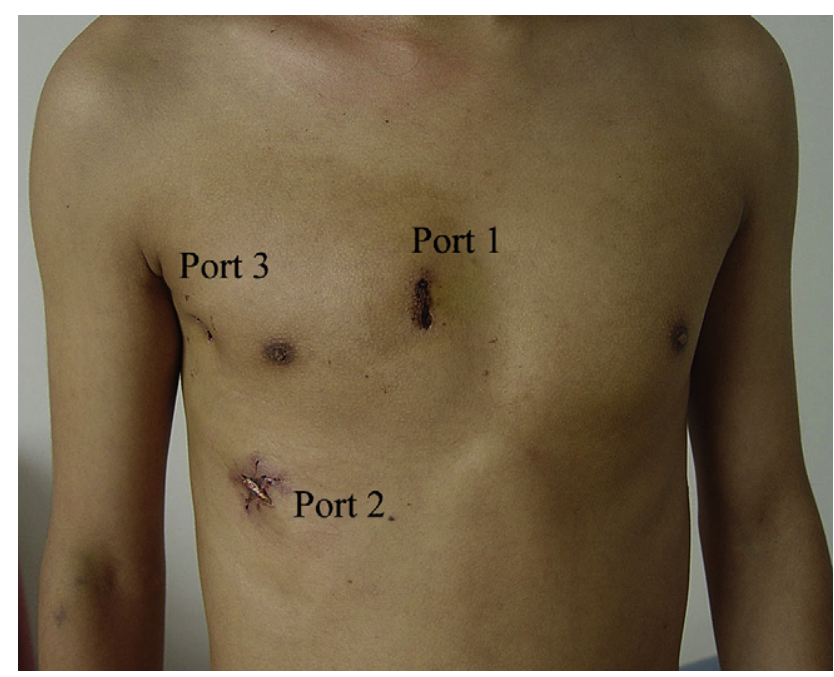

FIGURE 1. Location of the 3 ports on the right chest wall.

\section{Statistical Analysis}

SPSS version 13.0 software (SPSS, Inc, Chicago, Ill) was used for statistical analysis. Quantitative variables are expressed as means \pm standard deviations. Differences between multiple groups were compared by means of 1-way analysis of variance.

\section{RESULTS}

Fifty-eight patients with ASDs were initially screened, and 40 with secundum-type ASDs were finally enrolled in this study. The main reason for exclusion of patients was that they either had patent foramen ovale or small secundum-type ASDs, which were treated with percutaneous transcatheter closure by the cardiologists in our hospital. Five patients with large secundum-type ASDs were also excluded from this study because of high pulmonary arterial pressure $(>60 \mathrm{~mm} \mathrm{Hg})$. The general characteristics of the 40 selected patients are shown in Table 1 .

Totally thoracoscopic ASD repair was successfully performed in all patients, 33 with primary sutures and 7 with a bovine patch. Patients were subsequently discharged from the hospital 4 to 6 days after the operation. No patient underwent reoperation for bleeding. The mean CPB and aortic crossclamp times were $56.2 \pm 21.1$ minutes (range, 48-100 minutes) and $38.3 \pm 8.6$ minutes (range, 25-57 minutes), respectively. Once the aortic clamp was removed, heart beat resumed spontaneously in 35 patients. In 5 patients a 50-W DC shock through the chest wall was required to reboot the heart beat. The mean mechanical ventilation time was $3.2 \pm 1.2$ hours (range, $2-19$ hours), and the mean duration of intensive care unit stay was $23.0 \pm 4.1$ hours (range, 14-28 hours).

The total operative time, CPB time, aortic crossclamp time, mechanical ventilation time, and duration of intensive care unit stay of the first and second 10 patients and of the last 20 patients are listed in Table 2 . There is a significant 


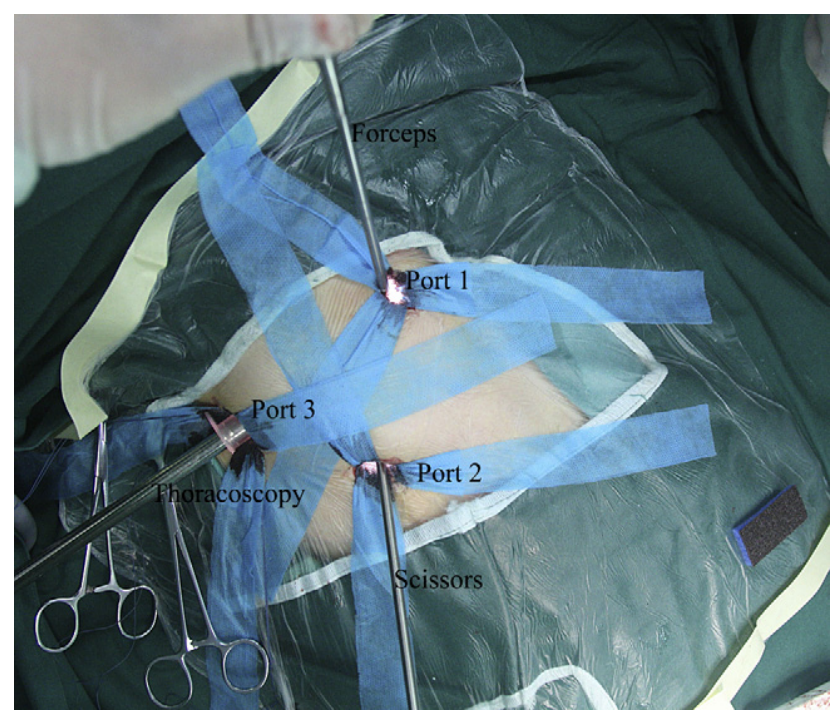

FIGURE 2. Function of each of the 3 ports.

reduction in total operative time, $\mathrm{CPB}$ time, and aortic crossclamp time in the last 20 patients $(P<.01)$.

Valvuloplasty with the De Vega technique was performed in 3 of the 5 patients immediately after ASD repair in the same procedure. Follow-up echocardiographic studies showed no tricuspid regurgitation in the 3 patients.

Eight $(20 \%)$ patients required intravenous fentanyl $\left(5-10 \mu \mathrm{g} \cdot \mathrm{kg}^{-1} \cdot \mathrm{h}^{-1}\right)$ for 1 to 2 days after the operation for pain relief. The remainder were treated with simple analgesics, mostly paracetamol. In all patients transesophageal echocardiographic analysis immediately after ASD repair showed complete closure with no residual shunt. One $(2.5 \%)$ patient experienced atrial fibrillation that spontaneously returned to sinus rhythm 4 hours after the operation. Three $(7.5 \%)$ patients required blood transfusion of $400 \mathrm{~mL}$ during the operation. Two $(5.0 \%)$ patients had right pulmonary atelectasis, which recovered within 24 hours

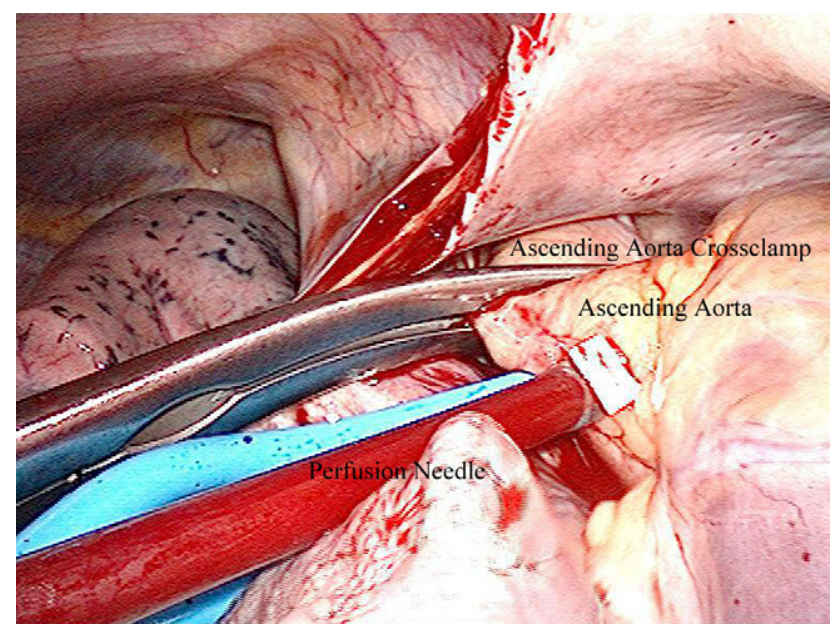

FIGURE 3. Ascending aortic crossclamp.

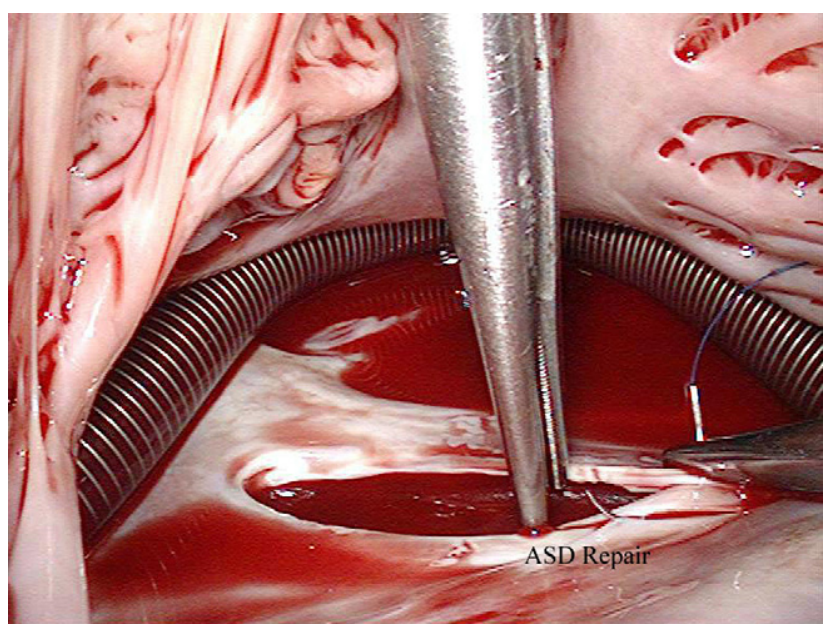

FIGURE 4. Repair of atrial septal defect (ASD).

after physiologic therapy on the chest. One $(2.5 \%)$ patient had right lung infection, which was successfully treated with antibiotics. The mean volume of the chest drain was $60 \pm 29 \mathrm{~mL}$ (range, 30-450 mL). Patients have been followed up for 2 to 9 months, with no signs of residual shunt on transthoracic echocardiographic analysis. There were no complications from the cannulation sites in the femoral vein or artery.

\section{DISCUSSION}

Since the introduction of robotically assisted cardiac surgery in 1997, ${ }^{11,12}$ there have been several studies on endoscopic repair of congenital cardiac defects, such as ASDs. Initially, this robotically assisted endoscopic technology was used to maximize visualization of intracardiac structures by providing enhanced endoscopic camera control and to facilitate the manipulation of surgical instruments through limited thoracic incisions. Later, several authors reported ASD repair entirely through thoracoscopic port incisions, with a high success rate and very few complications and with no need for conversion to full sternotomy or minithoracotomy. ${ }^{6-10}$ Totally endoscopic ASD repair minimized the degree of invasiveness, hastened postoperative recovery, and improved quality of life, although length of hospital stay was unchanged. ${ }^{9}$

TABLE 1. Baseline characteristic of the 40 selected patients

\begin{tabular}{lc}
\hline \multicolumn{1}{c}{ Indices } & Values \\
\hline Age $(\mathrm{y})$ & $15.4 \pm 8.7(6-47)$ \\
Male sex & $17(42.5 \%)$ \\
Body weight $(\mathrm{kg})$ & $36.6 \pm 14.6(20-90)$ \\
Diameter of ASD $(\mathrm{mm})$ & $26 \pm 5(18-36)$ \\
Mild pulmonary hypertension $(30-40 \mathrm{~mm} \mathrm{Hg})$ & $16(40 \%)$ \\
Moderate pulmonary hypertension $(41-60 \mathrm{~mm} \mathrm{Hg})$ & $3(7.5 \%)$ \\
Tricuspid regurgitation & $5(12.5 \%)$ \\
\hline Values in parentheses are ranges, where shown. $4 S D$, Atrial &
\end{tabular}

Values in parentheses are ranges, where shown. $A S D$, Atrial septal defect. 
TABLE 2. Comparison of operational data among three groups of patients

\begin{tabular}{lcccc}
\hline & $\begin{array}{c}\text { Patients } \\
\mathbf{1 - 1 0}\end{array}$ & $\begin{array}{c}\text { Patients } \\
\mathbf{1 1 - 2 0}\end{array}$ & $\begin{array}{c}\text { Patients } \\
\mathbf{2 1 - 4 0}\end{array}$ & $\begin{array}{c}\boldsymbol{P} \\
\text { value }\end{array}$ \\
\hline Total operative time (min) & $142 \pm 14$ & $116 \pm 9$ & $108 \pm 7$ & .015 \\
CPB time (min) & $70 \pm 8$ & $54 \pm 5$ & $50 \pm 4$ & .007 \\
Aortic crossclamp time (min) & $62 \pm 4$ & $51 \pm 4$ & $31 \pm 5$ & .019 \\
Mechanical ventilation & $4.1 \pm 0.7$ & $3.5 \pm 5.3$ & $3.0 \pm 6.5$ & .0001 \\
$\quad$ time (h) & & & & \\
Intensive care unit stay (h) & $26.1 \pm 5.2$ & $24.2 \pm 8.0$ & $18.1 \pm 4.3$ & .001 \\
\hline
\end{tabular}

Patients 21-40 included the 3 patients who received valvuloplasty in the same procedure. $C P B$, Cardiopulmonary bypass.

The currently used totally endoscopic techniques rely on a robotic surgical system, which might be a potential issue for some developing countries in which the high costs of these computerized systems could be ultimately passed on to patients. In this study, based on the previously reported endoscopic techniques, ${ }^{3-12}$ we derived a totally thoracoscopic approach for ASD repair without the aid of a robotically assisted surgical system. Successful repair of ASDs was achieved in all patients. The average CPB and aortic crossclamp times were 56 and 38 minutes, respectively. There were no major complications and no need for converting to full sternotomy or minithoracotomy. These data suggest that totally thoracoscopic repair of an ASD without robotic assistance is feasible and safe.

Similar to robotically assisted endoscopic techniques, our approach also faced learning curve issues, with longer CPB (70 minutes) and aortic crossclamp (62 minutes) times observed in the first 10 patients. Several investigators reported intraoperative data from robotically assisted ASD repair in a smaller number of patients, ranging from 10 to $17 .^{7,8,10}$ The mean CPB times in these reports varied from 122 to 161 minutes, and aortic crossclamp times ranged from 32 to 69 minutes. The mean $\mathrm{CPB}$ and aortic crossclamp times in our first 20 patients were comparable with those reported by the other investigators, $5,7,8,10$ except Argenziano and associates, ${ }^{8}$ who showed an aortic crossclamp time of 32 minutes. In our last 20 patients the CPB and aortic crossclamp times were reduced to 50 and 31 minutes, respectively. These data suggest that after the first 20 patients, an operator can achieve totally thoracoscopic ASD repair with relatively short CPB and aortic crossclamp times.

In conclusion, in patients with ASDs, totally thoracoscopic repair without robotic assistance is feasible. This technique is effective and safe and can be used as a therapeutic option for ASD.

\section{References}

1. DiBardino DJ, McElhinney DB, Kaz AK, Mayer JE Jr. Analysis of the US Food and Drug Administration Manufacturer and User Facility Device Experience database for adverse events involving Amplatzer septal occluder devices and comparison with the Society of Thoracic Surgery congenital cardiac surgery database. J Thorac Cardiovasc Surg. 2009;137:1334-41.

2. Austin EH. Transcatheter closure of atrial septal defects. J Thorac Cardiovasc Surg. 2003;125:85-6.

3. Black MD, Freedom RM. Minimally invasive repair of atrial septal defects. Ann Thorac Surg. 1998;65:765-7.

4. Doll N, Walther T, Falk V, Binner C, Bucerius J, Borger MA, et al. Secundum ASD closure using a right lateral minithoracotomy five-year experience in 122 patients. Ann Thorac Surg. 2003;75:1527-31.

5. Torracca L, Ismeno G, Alfieri O. Totally endoscopic computer-enhanced atrial septal defect closure in six patients. Ann Thorac Surg. 2001;72:1354-7.

6. Vistarini N, Aiello M, Mattiucci G, Alloni A, Cattadori B, Tinelli C, et al. Portaccess minimally invasive surgery for atrial septal defects: A 10-year singlecenter experience in 166 patients. J Thorac Cardiovasc Surg. 2010;139:139-45.

7. Wimmer-Greinecker G, Dogan S, Aybek T, Khan MF, Mierdl S, Byhahn C, et al. Totally endoscopic atrial septal repair in adults with computer-enhanced telemanipulation. J Thorac Cardiovasc Surg. 2003;126:465-8.

8. Argenziano M, Oz MC, Kohmoto T, Morgan J, Dimitui J, Mongero L, et al. Totally endoscopic atrial septal defect repair with robotic assistance. Circulation. 2003;108(suppl 2):191-4.

9. Morgan JA, Peacock JC, Kohmoto T, Garrido MJ, Schanzer BM, Kherani AR, et al. Robotic techniques improve quality of life in patients undergoing atrial septal defect repair. Ann Thorac Surg. 2004;77:1328-33.

10. Bonaros N, Schachner T, Oehlinger A, Ruetzler E, Kolbitsch C, Dichtl W, et al Robotically assisted totally endoscopic atrial septal defect repair: insights from operative times, learning curves, and clinical outcome. Ann Thorac Surg. 2006;82:687-93

11. Carpentier A, Loulmet D, Aupecle B, Kieffer JP, Tournay D, Guibourt P, et al Computer assisted open heart surgery. First case operated on with success. $C R$ Acad Sci III. 1998;321:437-42.

12. Falk V, Walther T, Autschbach R, Diegeler A, Battellini R, Mohr FW. Robotassisted minimally invasive solo mitral valve operation. J Thorac Cardiovasc Surg. 1998;115:470-1. 